\title{
Discrecionalidad e independencia del juez como base para la reforma de justicia en el Perú
}

\author{
JUAN MORALES GODO*
}

\begin{abstract}
SUMARIO: I. INTRODUCCIÓN.- II. LOS NUEVOS ROLES QUE PLANTEA EL NEOCONSTITUCIONALISMO.- III. DECISIÓN JUDICIAL Y ARGUMENTACIÓN JURÍDICA.- 1. CONTEXTO DE DESCUBRIMIENTO Y CONTEXTO DE JUSTIFICACIÓN. IV. DISCRECIONALIDAD JUDICIAL Y DECISIÓN JUSTA.- 1. DISCRECIÓN JUDICIAL Y JUSTICIA EN EL ESTADO DE DERECHO LEGALISTA. 2 EL PODER DEL JUEZ EN EL ESTADO CONSTITUCIONAL DE DERECHO. (LA CONSTITUCIÓN COMO LÍMITE DEL SISTEMA). V. INDEPENDENCIA JUDICIAL Y ARGUMENTACIÓN JURÍDICA.
\end{abstract}

\section{INTRODUCCIÓN}

¿Cuál es la función que les corresponde a los jueces en una sociedad democrática? Es una interrogante que nos motiva a indagar sobre las bases del sistema democrático. Encontraremos que la división de funciones que bosquejaron tanto Locke como Montesquieu, para garantizar el ejercicio democrático del poder, se han convertido en la estructura básica de todo sistema democrático hasta la actualidad.

Sin embargo, la preponderancia de algunas de las funciones ha variado con el transcurrir de los tiempos. En efecto, se le asignó un papel preponderante a la función legislativa, porque era la encargada de dictar las leyes, y sobre ella descansaba la racionalidad del sistema. Tanto la administración como la función jurisdiccional debían aplicar las leyes, sin tener mayores posibilidades de discrecionalidad en la interpretación, a no ser el tenor literal de la norma. El juez, en el Estado democrático liberal primigenio, se convirtió en la boca de la ley. Ello dio pie, durante un buen tiempo, al gran desarrollo de la corriente positivista en el campo del Derecho y al método de interpretación exegético.

Se genera el denominado Estado de derecho, que no viene a ser sino el sometimiento de los hombres al Derecho, y el Derecho eran las leyes. Sin embargo, el Estado de derecho tradicional se convirtió en una formalidad, de tal manera que los legisladores le otorgaban los contenidos más diversos y, en algunos casos, arbitrarios, sin respeto alguno por la norma suprema, la Constitución Política. 
En Europa continental se está produciendo una transformación en la comprensión del Derecho: se acerca al sistema del common law, que tiene una concepción del Derecho más abierta a la cultura y que gira alrededor de la Constitución. El poder discrecional del juzgador que caracteriza al sistema del common law está penetrando en el sistema europeo continental a través de la argumentación jurídica, sustentada en la interpretación de las normas constitucionales, lo que ha determinado que a esta corriente se le denomine el neoconstitucionalismo.

La corriente del neoconstitucionalismo le otorga al juez una posición singular dentro de la estructura del poder en un sistema democrático. Ya no es el legislador el elemento preponderante, al cual se sometía la función jurisdiccional ciegamente. Las normas que promulga la función legislativa ahora vienen sometidas a un ejercicio de validación constitucional por parte de los jueces. Las normas, se entiende, no son algo acabado que el operador aprehende para luego aplicarlo a la realidad mecánicamente, sino que el operador se convierte en el último momento, a través de la interpretación, y por lo tanto le otorga el contenido definitivo cuando lo aplica a un caso concreto de la realidad.

El juez, así, se convierte en el elemento preponderante en la estructura del poder en un sistema democrático. Ya no es la boca de la ley, como lo ideó Montesquieu, sino que es quien, a través de la discrecionalidad en la interpretación, le da el acabado final a la norma cuando la aplica a un caso concreto; además, ejerce un contrapeso en el ejercicio del poder de las otras funciones del Estado, a través del control de la constitucionalidad de las leyes, por medio del control difuso y del control concentrado, y en el defensor y garante de la vigencia de los derechos fundamentales de los ciudadanos.

\section{I।. LOS NUEVOS ROLES QUE PLANTEA EL NEOCONSTITUCIONALISMO}

En el mundo jurídico europeo se está produciendo una gran transformación en el enfoque general del Derecho y en la función social que este debe cumplir. El cambio fundamental gira alrededor del cuestionamiento a lo que tradicionalmente se ha denominado Estado de derecho. Esta es una noción que ha causado arraigo, que se prolonga hasta nuestros días, exitosa, porque implica el sometimiento del Estado ante el Derecho. Sin embargo, esta noción es muy amplia; se le puede dar —y de hecho así ha ocurrido- diversos contenidos. La realidad, que está circunscrita por intereses, se ha encargado de otorgar los más diversos contenidos, porque traduce finalmente la relación entre el poder y el Derecho. Desde los contenidos más apreciables, donde rescatamos la lucha contra la arbitrariedad en busca de la seguridad jurídica, hasta aquellos que consideraron que se trataba de una mera concepción formal, al cual le podríamos otorgar contenidos deleznables. Algunos Estados totalitarios 
han reclamado para sí la noción de Estado de derecho, porque formalmente cada una de las funciones de Estado cumplía con su deber, sin importar los contenidos. No interesaba tener un poder legislativo y judicial sometido a los dictados del poder. ${ }^{1}$

En la búsqueda de nuevas fórmulas, apreciamos un acercamiento del sistema jurídico europeo continental al sistema jurídico del common law. Quizás la diferencia esencial entre ambos sistemas es el papel que les corresponden tanto al legislador como al juez. La ley, dictada por el legislador, ha sido considerada por el juez como algo acabado, que debe aplicarse a los casos de la realidad sin mayores interpretaciones. ${ }^{2}$ Esto generó una corriente de mucha fuerza en el campo jurídico, que está vigente aún en nuestro medio: el positivismo jurídico. Se considera la ley como un fin y no como una herramienta que el sistema pone en manos del operador para que le pueda dar el contenido adecuado, con el objetivo de resolver el caso concreto. El argumento fundamental es que ello brinda seguridad jurídica, que elimina la posibilidad de la arbitrariedad del juzgador. La corriente exegética de interpretación de las leyes se pone al servicio del positivismo. En este sentido, el papel del legislador cobra un papel preponderante. Él hace la ley y el operador se limita aplicarla, sin que exista posibilidad de ir en contra «del texto expreso», porque incurriría en prevaricato, ilícito penal previsto en nuestra legislación, que limita severamente las posibilidades de interpretación del juzgador.

Esta forma de entender el Derecho y el papel que juegan el legislador y el juez han sido cuestionadas por los europeos, con lo que se ha generado una nueva teoría denominada constitucionalismo moderno o neoconstitucionalismo, que descubre nuevos roles en los actores del Derecho, que cuestiona el tradicional Estado de derecho, y que perfila y prefiere el Estado constitucional. Desde esta perspectiva, el poder se somete a la Constitución, no solo a la ley, en la que existen mayores dificultades de manipulación para los gobernantes de turno. ${ }^{3}$

La Constitución, como norma suprema de un Estado democrático, fija los contenidos a través de prescripciones de conductas, al recoger los valores que la sociedad quiere privilegiar. El pacto social se traduce en opciones que las mayorías han determinado a través de la designación de una asamblea constituyente. Gobernantes, gobernados, legisladores, jueces y todos los que están relacionados con el quehacer jurídico deben responder ante la carta suprema. Los legisladores, al dictar las leyes, no pueden contrariar caprichosamente los mandatos constitucionales, plasmados en derechos, principios y valores. Los jueces cumplen

1 Zagrebelski, Gustavo. El Derecho dúctil. Madrid: Trotta, 1995, p. 24.

2 «No existe verdad en el Derecho, porque no hay ningún mundo previo: el Derecho no es algo que esté ahíy quehayquedescubrirsino, más bien, esalgoporhacerquehayqueinventardentrodeloslímitesimpuestos por el texto de la ley [...]”. De Trazegnies Granda, Fernando. Pensando insolentemente. Lima: Fondo Editorial PUCP, 2001, p. 49.

3 Gascón Abellán, Marina y Alfonso García Figueroa. La argumentación en el Derecho. Lima: Palestra, 2003, p. 21.

DISCRECIONALIDAD E INDEPENDENCIA DEL JUEZ COMO BASE PARA LA REFORMA DE JUSTICIA EN EL PERÚ 
la función excelsa de controlar la constitucionalidad de las leyes, en nuestro medio, a través del órgano concentrado del Tribunal Constitucional y a través del control difuso, en el caso del Poder Judicial.

En el Estado constitucional no solo se cuestionan el positivismo decimonónico y la noción del llamado Estado de derecho, sino también el principio de legalidad.

Existen razones históricas de carácter universal que tienen que ver con el papel de la ley en los sistemas legislativos. En efecto, con el advenimiento de la Revolución francesa, opera un cambio importante en lo que se refiere a la administración del Estado. Recordemos que desde aquella época surge la concepción de los tres poderes del Estado; es cuando cobra especial preeminencia el Poder Legislativo, esto es, el generador de las leyes.

El Estado legislativo hace que cobre especial relevancia el legislador y relega a los operadores, quienes debían cumplir estrictamente lo señalado en las leyes. Así, el juez se convierte en la «boca de la ley», ni qué decir del operador administrativo. Se parte de la desconfianza, justificada por razones históricas, de tal manera que el juez, para decir el derecho, debía remitirse, necesaria y únicamente, a la ley, y era severamente reprimido cuando se apartaba de ella. Así se genera lo que en el siglo XIX se denominó el Estado de derecho, esto es, un Estado que regulaba la conducta de los gobernantes y gobernados en función a la ley. Como señala Zagrebelski, «El Estado de derecho y el principio de legalidad suponían la reducción del derecho a la ley y la exclusión o, por lo menos, la sumisión a la ley, de todas las demás fuentes del derecho [sic]». ${ }^{4}$

Pero la ley, además, tenía el «privilegio» de encarnar la racionalidad del sistema político que los revolucionarios franceses intentaban plasmar, frente a la arbitrariedad del poder absoluto. La razón, entonces, no podía encontrarse en las decisiones de las cortes, ni menos de los tribunales administrativos, ya que ellos debían remitirse necesariamente a la ley, sobre la descansaba la razón.

Esta manera de ver el Derecho como instrumento que regula la conducta de los gobernantes y gobernados, comparativamente, significó un avance frente a la arbitrariedad de los gobernantes de épocas anteriores. Sin embargo, terminó por privilegiar al legislador, con el argumento de que era el único legitimado socialmente para producir el Derecho. Se identificaron Derecho y norma, y la norma la dictaba el legislador con el poder político consiguiente. ${ }^{5}$

4 ZaGRebelskı, Gustavo. Loc. cit. Señala, el autor, además, que la ley expresa la idea de un acto normativo supremo e irresistible. El Estado liberal de derecho se sustentaba en la primacía de la ley frente a la administración, lajurisdicciónyalospropiosciudadanos. ElprincipiodelegalidadfueelsustentodelEstado liberal de derecho, que se convirtió en un Estado legislativo.

5 Nieto, Alejandro. El arbitrio judicial. Barcelona: Ariel, 2000, p. 322. 
Pronto, sin embargo, el contenido de la ley se produjo en función de los intereses políticos económicos de turno, y en el siglo XX surgieron gobiernos que pretendieron escudarse detrás de la concepción del Estado de derecho, para justificar, a través de la ley, acciones contrarias a la dignidad del ser humano. Bajo la formalidad de la ley se escondían intereses subalternos de los grupos dominantes. Pronto se toma conciencia de ello y de la fragilidad de hacer descansar sobre la ley todo el peso del Derecho.

Precisamente, comienzan a redactarse las constituciones, en las que no solo se establecen las reglas de organización de un Estado, sino que se entiende como la norma que protege los derechos fundamentales del ser humano. Del Estado de derecho, pasamos hoy al Estado constitucional, que hace descansar sobre la Constitución, ley fundamental indiscutible, la referencia para la regulación de la relación entre gobernantes y gobernados. ${ }^{6}$ Entiéndase que en una Constitución se recogen las instituciones que van a articular el ejercicio del poder, pero, además, los valores preeminentes que una sociedad decide privilegiar, para construir una sociedad auténticamente democrática. De la misma forma, surge la justicia constitucional, que orienta su labor, precisamente, a hacer valer la Constitución como norma fundamental del ordenamiento jurídico.

A partir de ello, se puede decir que el control de legalidad, en realidad, ha devenido en un juicio de constitucionalidad. «La ley —anota Zagrebelski- por primera vez en la época moderna viene sometida a una relación de adecuación y, por tanto, de subordinación a un estrato más alto de derecho establecido por la constitución».

¿Cuál es el papel del juez en un Estado constitucional? Evidentemente, no es el mismo papel que ha desempeñado en un tradicional Estado de derecho. En un Estado constitucional, cobra preponderancia su actuación. La norma no es un modelo acabado que se trasplanta a la realidad. Es una propuesta del legislador, cuyos contenidos tienen que ser acabados por el juzgador cuando la aplica a un caso concreto. En ese sentido, el actor principal del Derecho resulta ser la función jurisdiccional y no la legislativa, el juez y no el legislador. Como lo ha señalado Fernando de Trazegnies, «el legislador ha muerto»?

En el Estado de derecho tradicional, la interpretación estaba totalmente restringida bajo el entendimiento que era el gobierno de las leyes y no de los hombres. Lo más clamoroso, que lamentablemente persiste aún en nuestro sistema jurídico, es la exigencia de que el juez se pronuncie en los casos que resuelve, sin apartarse del texto expreso de la norma, pues de lo contrario sufriría una sanción por prevaricato. Las normas se

6 Pietro Sanchís, Luis. Derechos fundamentales y neoconstitucionalismo y ponderación judicial. Lima: Palestra, 2002, pp. 121-122.

7 De Trazegnies Granda, Fernando. Op. cit., p. 50. Una de las ideas centrales del distinguido autor peruano es que el Derecho no es algo acabado, sino que es permanente creación a través de la interpretación de las normas. El intérpretecobra papel importante porquecompletalaetapafinal del proceso de la norma que no acaba con la propuesta del legislador, sino con la interpretación del operador del Derecho.

DISCRECIONALIDAD E INDEPENDENCIA DEL JUEZ COMO BASE PARA LA REFORMA DE JUSTICIA EN EL PERÚ 
aplican en su sentido más estricto y mediante un simple análisis lógico. Dura lex sed lex. Preguntarse si con esta aplicación se hacía justicia no estaba dentro de las responsabilidades del juzgador.

En un Estado constitucional, la interpretación es un tema esencial. Los métodos de interpretación en general son útiles para encontrar los argumentos que justifiquen una decisión. Ningún método es mejor que el otro. Todos los métodos son buenos si nos brindan los argumentos para justificar una decisión que debe ser razonable, socialmente aceptable y justa. La relación norma-caso es fundamental. La interpretación debe relacionar estos dos aspectos, la ley y el caso concreto, la ley y la realidad. Solo la norma nos conduciría a teorizar sin mayor concreción con la realidad; si fuese solo el caso, convertiríamos el Derecho en un tema casuístico, sin parámetros definidos. La jurisprudencia debe ser la consecuencia del cotejo entre la norma y la realidad. Por ello se afirma que la manera natural de evolución del Derecho es la jurisprudencia, evidentemente, cuando relaciona la ley con la realidad.

Esta interpretación que se realiza al cotejar la ley con el caso concreto va a depender de la estructura de la ley. Algunas utilizan cláusulas generales como «buena fe», «buenas costumbres», «interés público», etcétera, que se traducen en un campo abierto para la interpretación por parte del juez. En otras leyes más concretas, los márgenes de interpretación no son tan amplios, pero siempre el juzgador puede «reconducir a ley las exigencias de regulación que presenta el caso».

De otro lado, el caso no es una mera secuencia histórica de los hechos, sino que se trata de hechos que deben ser resueltos por el juzgador, y en estos casos hay que encontrarles un sentido y un valor: solo así podemos encontrar una solución adecuada al caso.

\section{DECISIÓN JUDICIAL Y ARGUMENTACIÓN JURÍDICA}

Como señalara Atienza, nadie duda en que la práctica del Derecho consiste, de manera fundamental, en argumentar, y todos solemos convenir en que la cualidad que mejor define lo que se entiende por un «buen jurista» tal vez sea la capacidad para idear y manejar argumentos con habilidad. ${ }^{8}$

De entrada diremos que las decisiones judiciales no siempre requirieron de una justificación (argumentación) que las sustente. Y esto determinado por las corrientes ideológico-jurídicas dominantes en cada etapa histórica de una determinada sociedad.

Así tenemos que, por ejemplo, las dos clásicas y antagónicas posiciones extremistas (ius naturalismo racionalista y el positivismo formalista) 
partían de la idea de la plenitud y perfección de sus fuentes y de la unidad de la solución justa.

El orden medieval estuvo basado sobre nociones de revelación y salvación, a las que sucede una rigurosa y secularizada lógica cartesiana que tanto estimuló a los iusnaturalistas del siglo XVII para la elaboración de un pensamiento constructivo y sistemático, no fiduciario de voluntades inescrutables; se trataba de iusnaturalistas que, a su vez, serían poco a poco desplazados por lo que se ha denominado la generalización del paradigma newtoniano, anunciador de una razón menos especulativa y metafísica, más volcada a la acción y a la vida, que es justamente una característica definitoria de la filosofía de la ilustración.

Siguió después una corriente voluntarista, que identificaba el Derecho con la voluntad de una persona o de un órgano determinado. Quizás sea Hobbes, racionalista y al mismo tiempo precursor del positivismo, quien de forma más concluyente levantase el acta de la nueva realidad del Estado moderno. Se pasó luego a los formalismos positivistas propugnados por las distintas escuelas (exegética, historicismo, jurisprudencia analítica) de Francia, Alemania e Inglaterra, respectivamente.

Fue en el imperio del paradigma del formalismo positivista donde la actividad argumentativa se vio extremadamente limitada, ya que no cabía interpretación alguna de unos cuerpos legislativos que se consideraban perfectos y plenos (códigos). La interpretación era innecesaria, ergo, la argumentación inexistente, ya que el juez es la simple boca que pronuncia las palabras de la ley (juez irresponsable).

La reacción ante el formalismo comienza a formarse a partir de la toma de conciencia de las insuficiencias de la lógica formalista aplicada al Derecho. Se reconoce a Ihering como el precursor de esta corriente, que devino después en la jurisprudencia de intereses de Heck, que propugnaba en la actividad jurisdiccional un compromiso más funcional con la realidad, y que buscó ubicarse en medio del positivismo más radical y del Derecho libre de Geny. Este, junto con algunas expresiones de los realismos americanos y escandinavos, constituye las impugnaciones más radicales del logicismo jurídico.

Ahora bien, junto con estas corrientes realistas y liberales - tachadas de irracionales, ya que la aplicación del Derecho provendría más de impulsos volitivos que de operaciones lógicas-, por los años cincuenta surgieron otros esfuerzos teóricos con la finalidad de conferir racionalidad al proceso de interpretación y aplicación del Derecho. Surge así la tópica de Theodor Viehweg, quien parte de la disyuntiva planteada por el filósofo Nicolai Hartman entre pensamiento sistemático y pensamiento problemático. El pensamiento problemático — también llamado aporético - parte del problema. Se tenía que desarrollar un método que permitiera encontrar las premisas y estas, a su vez, debían apoyarse sobre puntos de vista probados o prestigiosos (tópicos). Después tenemos a 
Chaïm Perelman, para quien la argumentación consiste en un ejercicio de retórica, esto es, en una práctica tendente a captar la adhesión de algún auditorio. ${ }^{9}$

Cuando hablamos de argumentar, aludimos a una actividad que evidentemente no es privativa de los juristas. Se argumenta en todos los ámbitos del quehacer humano, desde los más calificados hasta los más triviales y domésticos. ¿Qué es entonces lo que convierte a una argumentación en jurídica?

La respuesta a esta pregunta nos la da la teoría estándar de la argumentación jurídica, propugnada principalmente por Neil MacCormick y por Robert Alexy. Esta teoría supondría un avance frente a sus predecesoras de los años cincuenta, porque añade la distinción proveniente de la filosofía de la ciencia, de un contexto de descubrimiento y de un contexto de justificación, y la dualidad de la función justificatoria (interna-externa) y, por tanto, la admisión de la lógica formal en el Derecho, siempre con las reservas que impone su insuficiencia en el razonamiento jurídico.

Las teorías estándar de la argumentación jurídica tienen lugar en contextos jurídicos. Pueden distinguirse tres: el primero de ellos es el de la producción o establecimiento de normas jurídicas. Aquí a su vez podrían distinguirse entre argumentos que se presentan en una fase pre-legislativa y los que se producen en la fase legislativa. Los primeros se efectúan como consecuencia de la aparición de un problema social cuya solución, se piensa, puede ser la adopción de una medida legislativa, por ejemplo, la penalización del aborto. Otro tipo de argumentaciones surgen cuando un problema pasa a consideración del parlamento o de algún órgano de la administración. Mientras que en la fase pre-legislativa puede considerarse que los argumentos tienen, por lo general, un carácter más político y moral que jurídico, en la fase legislativa los papeles se invierten, de manera que son las cuestiones de tipo técnico-jurídico las que pasan a un primer plano. En todo caso, las teorías estándar de la argumentación jurídica no se ocupan prácticamente de ninguno de esos dos contextos de argumentación.

Un segundo campo en que se efectúan argumentos jurídicos es el de la aplicación de normas jurídicas o el de la resolución de casos. Finalmente, el tercer ámbito de argumentación sería el de la dogmática jurídica. ${ }^{10}$

\section{Contexto de descubrimiento y contexto de justificación}

La motivación de las decisiones judiciales constituye uno de los elementos fundamentales de un Estado democrático como conquista frente a las arbitrariedades en que pudiera incurrir el intérprete juzgador. Ahora, motivar no es expresar móviles íntimos psicológicos. Por ejemplo, si 
decimos que Carla mató a Otelo motivada por los celos, los celos explican la acción asesina, pero no la justifican. Igualmente, a la teoría de la argumentación estándar no le interesan los motivos del juez para dictar una determinada sentencia -ideología, fobias, problemas personales, filias etcétera-, cuanto las razones jurídicas que fundamentan esa sentencia.

Se entiende por razones jurídicas no solo la exposición de razones fundadas en leyes positivas (textos escritos), sino también las sustentadas en principios constitucionales y en tests de razonabilidad y proporcionalidad. Vale decir que no es suficiente que una decisión judicial esté ajustada a lo prescrito por el texto de una ley para considerarse justificada y satisfactoriamente argumentada, sino que también deberá pasar el test de razonabilidad, bajo pena de ser tachada de irrazonable, ergo arbitraria, aunque esta sea legalmente pulcra.

Cabe hablar de una justificación formal de los argumentos — cuando un argumento es formalmente correcto- y de una justificación material - cuando puede considerarse que un argumento, en un campo determinado, resulta aceptable o razonable- . Ello permite distinguir entre la lógica formal o deductiva, por un lado, y lo que a veces se llama lógica material o informal, razonable - en donde se incluirían la tópica o la retórica-, por el otro. La teoría estándar de la argumentación jurídica se sitúa, precisamente, en esta segunda perspectiva. ${ }^{11}$

\section{DISCRECIONALIDAD JUDICIAL Y DECISIÓN JUSTA}

\section{Discreción judicial y justicia en el Estado de derecho legalista}

Históricamente, en Europa el Estado de derecho es la forma de Estado que nace con la Revolución francesa, cuyo objetivo había sido garantizar la libertad y la igualdad de los ciudadanos y acabar con los privilegios del clero y de la nobleza. El Estado de derecho es una ideología jurídica y responde a la idea de un gobierno sub leges y per leges: el gobierno de la ley frente al gobierno de los hombres. ${ }^{12}$ En esos tiempos, hablar de justicia equivalía a hablar de legalidad. Justa era la conducta conforme a ley, e injusta la contraria.

La sumisión de la administración a la ley se establece en términos de subordinación. La administración solo puede actuar previa habilitación legislativa, lo que significa que para ella rige el principio «todo lo que no está permitido está prohibido», y el órgano jurisdiccional, al ser considerado como un órgano más de esta administración, tuvo el mismo tratamiento. La administración de justicia en nombre del pueblo

DISCRECIONALIDAD E INDEPEN-

DENCIA DEL JUEZ

COMO BASE PARA

LA REFORMA DE JUSTICIA EN EL PERÚ 
se transformó desde su inicio, para Francia, Europa occidental y toda su zona de influencia, en una permanente sujeción de los jueces a los mandatos del Ejecutivo o, en ocasiones, del Legislativo. Esta situación surgió de un hecho elemental: el control del nombramiento de los jueces. Dado que en este acto no se reconoció un origen popular del juez, la condición marginal del juez lo condujo a convertirse en un funcionario público más, y su labor pasó a ser una simple actividad administrativa. ${ }^{13}$

Es evidente que a un simple funcionario más de la administración no se le puede pedir que busque la justicia en sus decisiones; a lo sumo se le puede exigir que actué legalmente, pues de lo contrario incurriría en responsabilidad en virtud al principio de libertad negativa (legalidad) que rige la actuación de la administración pública.

Los jueces solo tienen una legitimidad de "técnica», y esta vinculación a la ley configura la base de un modelo de juez que le es propio al Estado de derecho legal. Se trata del juez neutral, sin ideología, aséptico, apolítico. Es la boca que pronuncia las palabras de la ley. Y, así, garantizar la certeza y previsibilidad de las decisiones judiciales y la igualdad en la aplicación de la ley se convierte en su objetivo existencial. Hablar de discrecionalidad, en estas circunstancias, resultaba herético.

Pero sucede que, generalmente, los problemas fundamentales de toda interpretación textual nacen de la vaguedad y de la ambigüedad de los textos sujetos a la interpretación. ${ }^{14}$ Generalmente, los documentos normativos son formulados no ya en un lenguaje artificial - en el que todos los términos y todos los conectivos sintácticos están rigurosamente definidos- sino en un lenguaje natural, y el lenguaje natural no está sujeto a reglas semánticas y sintácticas bien definidas. Los enunciados del lenguaje natural son, por lo tanto, fatalmente indeterminados.

Es así que se comienza a conceder al juez márgenes de interpretación, con una discrecionalidad que proviene de la misma naturaleza de la actividad interpretativa de los textos; pero, siempre dentro del principio de legalidad y tendente a buscar una mítica voluntad del legislador. El juez estaba vinculado al sistema jurídico legalista porque el Derecho terminaba en la ley.

\section{El poder del juez en el Estado constitucional de dere- cho. (La Constitución como límite del sistema)}

Históricamente, el Estado constitucional de derecho es la forma política que cuajó en el constitucionalismo anglosajón, que se fue expandiendo a otros sistemas jurídicos en los que, junto a la ley, existe una constitución democrática que establece auténticos límites jurídicos al poder para 
garantizar las libertades y los derechos de los individuos y que tiene, por ello, carácter normativo.

El Estado constitucional es un estadio más de la idea de Estado de derecho o, mejor, su culminación: si el Estado legislativo de derecho había supuesto la sumisión del juez a la ley, el Estado constitucional de derecho supone que este y también el legislador vienen sometidos al Derecho, en este caso, a la Constitución.

Es en este contexto que las decisiones justas ya no se agotan en la correspondencia con el texto legal, sino - principalmente- con la correspondencia con los principios constitucionales. Es entonces que la vinculación del juez al sistema jurídico se extiende hacia algo más abstracto e impreciso, como los principios, límite de clausura del sistema.

Ahora bien: Michele Taruffo nos propone como criterios para la delimitación de una decisión justa los siguientes:

a) la corrección de la elección y de la interpretación de la regla jurídica aplicable;

b) la comprobación fiable de los hechos relevantes del caso; y

c) el empleo de un procedimiento válido y justo para llegar a la decisión. ${ }^{15}$

En realidad, este es un criterio más que se podría utilizar para la delimitación de lo que es justo y de lo que no lo es; pero lo cierto es que, en Derecho, la formulación de criterios generales es siempre relativa y contingente. Ello ocurre sobre todo cuando se refiere al concepto de justicia, que más pareciera corresponder a un sentimiento, a una idea que cada sujeto tiene y que comparte con su grupo social, al tener en común determinados valores y pautas de conducta existenciales básicos. Y al ser la justicia un sentimiento fundado sobre valores, entonces nos ubicamos en el ámbito del conocimiento de los objetos ideales, objetos que son conocidos de manera intuitiva e inmediata, como diría Descartes, y que se apreciarían en cada caso de manera peculiar.

Luis Recasens Siches decía que todas las definiciones de la razón, que hacían consistir lo esencial de esta en ciertos modos particulares de operar en el intelecto, además de ser estrechas, la han esterilizado y le han amputado y embotado su dimensión decisiva:

Para mí es razón — decía Recasens Siches— en el verdadero y riguroso sentido, toda acción intelectual que nos pone en contacto con la realidad, por medio de la cual topamos con lo trascendente. Lo demás no es sino puro intelecto, mero juego casero y sin consecuencias, que primero divierte al hombre, luego lo estraga y, por fin lo desespera y le

DISCRECIONALIDAD E INDEPENDENCIA DEL JUEZ COMO BASE PARA LA REFORMA DE JUSTICIA EN EL PERÚ 
hace desperdiciarse a si mismo. Cada caso es diverso y por ello el derecho [sic] es esquivo a las generalizaciones, las sistematizaciones y los métodos de la ciencia. ${ }^{16}$

Lo cierto es que el advenimiento del Estado constitucional deja un amplio margen de discrecionalidad a los operadores del Derecho para fundar sus decisiones de acuerdo con lo que consideren justo en cada caso. Los casos denominados «fáciles» — casos de evidente injusticia de una posible decisión conforme con la ley- son susceptibles de una ponderación a través de los tests de razonabilidad y proporcionalidad para resolver de acuerdo con el sentir común de justicia. Es mayor aún la discrecionalidad en los casos «difíciles» —en los que cualquiera de las decisiones son controvertibles-, ya que el intérprete no estará vinculado con un sentir común de justicia.

\section{INDEPENDENCIA JUDICIAL Y ARGUMENTACIÓN JURÍDICA}

Una de las expresiones concretas del Estado de derecho es haber perfilado y definido la función jurisdiccional como independiente de las funciones legislativa y ejecutiva. De nada hubiera servido que la función de resolver los conflictos quedase en manos de los que hacen las leyes o del Ejecutivo, que concentra la fuerza coercitiva. Por ello, la independencia no solo es un valor, sino una garantía para los gobernados. ${ }^{17}$

Por otro lado, la independencia de los jueces tiene que plasmarse, concretamente en cada caso, cuando interpretan las normas. El juez boca de la ley no es precisamente la mejor demostración de la independencia del juzgador. Tiene que existir una suerte de valor agregado que el juzgador le otorga a la norma al resolver un caso.

La independencia judicial como garantía dependerá de un conjunto de factores jurídico-políticos, aun al tratarse de los Estados democráticos. No basta decir, en abstracto, que la función judicial es independiente, sino que ello tiene que traducirse en el plano de las realidades, fundamentalmente en las decisiones que adopten los jueces en los casos concretos.

En el common law anglosajón, se configuró la independencia judicial después de arduas e históricas batallas. En la actualidad, la expresión de dicha independencia se presenta en la inamovilidad y no responsabilidad del juez y en la libertad para tomar determinaciones cotejadas con los precedentes judiciales. Los jueces, una vez elegidos, no pueden ser removidos, salvo por resolución de ambas cámaras del parlamento, lo que constituye un verdadero juicio político. Por otro lado, no son 
responsables por las decisiones que adopten en los procesos en los que intervienen. En el caso de los Estados Unidos de Norteamérica, estas garantías que tienen los jueces están constitucionalizadas. Si bien se trata de aspectos institucionales que brindan un marco para la actuación de los jueces, son aspectos importantes porque garantizan la actuación independiente de los jueces norteamericanos. ${ }^{18}$

En el caso de los jueces de Europa continental, en relación con el tema de la independencia, existen razones históricas que la diferencian de Inglaterra. La preponderancia del legislador fue determinante. No solo se prohibía a los jueces interpretar las leyes, sino que se le prohibía todo tipo de fiscalización a las otras funciones del Estado. Evidentemente, se perfiló un juez distinto del anglosajón. La selección y el nombramiento de los jueces se realizaban a través del Poder Ejecutivo. Se estableció la carrera judicial, con lo que apareció la figura del juez-funcionario. El juez no es un profesional experimentado y prestigioso que, como culminación de su carrera, es llamado a la judicatura, sino un abogado que aspira a hacer carrera a través de los distintos escalones de la función. En este sistema, que también es el que impera en Latinoamérica, los problemas centrales en torno del tema de la independencia judicial son el ingreso a la judicatura, la inamovilidad en el cargo y la responsabilidad por sus actos, entre otros. ${ }^{19}$

Dentro del sistema jurídico peruano, se ha avanzado en cuanto al modelo de elección de los magistrados — aunque aún es necesario insistir en su perfeccionamiento-, tanto en lo que se refiere a su conformación como al sistema de evaluación y designación de aquellos. En cuanto al tema de la inamovilidad en el cargo, es una verdadera espada de $\mathrm{Da}$ mocles la que sufren los jueces, no solo por los procesos de ratificación que, en nuestro concepto, son inconstitucionales, sino por el incipiente e inconsistente sistema democrático, permanente y abruptamente interrumpido, siempre utilizando como pretexto la situación de ineficacia y corrupción del Poder Judicial.

Además de los temas indicados, que giran alrededor del tema de la independencia, hemos señalado que esta se expresa concretamente en las decisiones judiciales, es decir, en la imparcialidad con que debe proceder el juez. Sin embargo, es imposible plasmar esta imparcialidad si no se toma conciencia de lo que realmente realiza el juez al dictar una sentencia, esto es, al argumentar. Cuando el juez motiva una decisión, debe argumentar, y ello implica explicar y, fundamentalmente, justificar. Existen razones explicativas y razones justificativas y estas últimas quizás sean las más importantes en el campo del Derecho. Uno de los mayores problemas de la judicatura peruana es el razonamiento jurídico, específicamente en lo referido a la justificación de las decisiones que 
se adoptan en los procesos judiciales. Generalmente explican, pero no justifican por qué concluyen en una forma y no en otra.

Una de las expresiones reales de auténtica independencia se manifiesta cuando el juez resuelve, lo que no siempre ocurre con los demás actores del Derecho, quienes no necesariamente deben responder a este valor. Se discute si el juez debe resolver de acuerdo con lo que le señala expresamente la ley (gobierno de las leyes) o si la interpretación debe pasar por un proceso de validación y de cotejo con los valores imperantes en una colectividad, recogidos por la normatividad, especialmente por la Constitución Política del Estado (gobierno de los hombres). La noción de gobierno de las leyes lleva consigo la predominancia del legislador frente a los demás operadores, incluido el juez. Sin embargo, las leyes siempre generan dos o más opciones de solución, y es deber del juez escoger, como producto de su razonamiento jurídico, la solución más razonable, socialmente aceptable y justa.

En consecuencia, los deberes de independencia e imparcialidad constituyen deberes del juez y son las características más destacadas de un Estado de derecho. El juez debe resolver conforme con los elementos que le brinda el Derecho. Es una garantía que los ciudadanos sean juzgados desde las perspectivas de esta disciplina. La norma, sin embargo, no es el único elemento del Derecho: están los valores y la vida humana, traducida en las realidades sociales, económicas y culturales. Ya no es concebible un juez como mero aplicador de la ley: un juez boca de la ley pertenece al pasado. Para el juez actual, su independencia e imparcialidad se traducen en la exigencia de racionalidad de las decisiones, y ello está vinculado con la argumentación jurídica. Una decisión razonable es una decisión que contiene argumentos que la justifican, en la que encontraremos razones lógicamente expresadas.

En el caso peruano, la argumentación jurídica, que se convierte en una verdadera herramienta para la independencia en el actuar del juez, es extraordinariamente deficiente, debido a la formación que se brinda en las universidades a los estudiantes de Derecho. La enseñanza es esencialmente normativa y con predominio de la interpretación literal o gramatical, de tal forma que difícilmente podemos extraer argumentos fuera de los alcances de la literalidad. Se complica el tema cuando se le exige al juez que resuelva de acuerdo con el texto expreso de la norma; caso contrario, será pasible de sanción disciplinaria o de denuncia penal por delito de prevaricato.

Como primeros pasos para una reforma de la justicia en el Perú, se debe modificar el contenido del ilícito penal de prevaricato y revisar el sistema de enseñanza del Derecho en las universidades, pues están estrechamente vinculados con el poder discrecional y con la independencia de los jueces. 